por

\title{
MANUELA MARIN
}

Instituto de Filología, C.S.I.C.

RESUMEN: A partir de la guerra hispano-marroqui de 1860, la literatura de viajes sobre Marruecos conoce un gran desarrollo en España. En la primera parte de este artculo se ofrece una tipologta de los autores de este tipo de obras, fundada en su actividad profesional (exploradores, militares, diplomáticos, periodistas y cientificos). La segunda parte está dedicada al analisis del discurso empleado en estos libros de viajes, cuya representación de la realidad marroquí se sitúa en el marco de una ideologia de carácter colonial.

PaLABRAS CLAVE: Viajes. Marruecos. España, siglo xIx. Colonialismo.

ABSTRACT: Spanish travel literature on Morocco began a major development after the Spanish-Moroccan war of 1860. This article presents a survey of this literature in two parts. First, an analysis of the authors provides a typology of Spanish travellers based mainly on their profesional activities (explorers, military men, diplomats, journalists and men of science). The second part analyzes the rhetoric used by the travellers, whose representation of Moroccan reality is placed in the ideological framework of colonial expansion.

KeY WORDS: Travels. Morocco. 19th century Spaln. Colontalism.

La publicación en 1978 del estudio de E. Said Orientalism, provocó, entre otras cosas, la apertura de un debate sobre la política cultural de Occidente que está aún lejos de agotarse. Orientalism se ha convertido así en la referencia inexcusable para cualquier intento de análisis sobre la interacción Oriente/Occidente y sus mismos críticos no han dejado de observar la importancia de la contribución de Said a un tema que hasta entonces no había suscitado una atención excesiva fuera de círculos de 
especialistas 1. La riqueza y la calidad de esas críticas - o de una gran parte de ellas- son, por otro lado, el mejor reconocimiento a un texto en cierto modo inaugural, como es éste. Una de ellas es la que me permite introducir el tema que voy a desarrollar a continuación. En efecto, se ha reprochado a Said que su interprentación del orientalismo produce una visión demasiado homogénea y compacta, en la que se tiene muy poco en cuenta la diversidad de tradiciones orientalistas occidentales y los diferentes contextos históricos y culturales en que se han producido, así como sus contradicciones internas. Y ello ha ido produciendo una serie de aportaciones destinadas a completar y matizar el panorama de los discursos occidentales sobre el Oriente ${ }^{2}$. A esta heterogeneización del orientalismo clásico pretenden contribuir estas páginas, dedicadas a reconstruir, siquiera parcialmente, la visión española sobre Marruecos en el siglo XIX.

Los textos que se escriben en España en esa época acerca de la sociedad marroquí son de muy diverso carácter y motivaciones, pero todos ellos se componen sobre el trasfondo de la intervención española en el Norte de África. Hay toda un producción periodística y política e incluso literaria sobre Marruecos que sería imposible de tratar en un breve artículo como éste y que ha sido objeto de algunos estudios parciales ${ }^{3}$. En esta ocasión he seleccionado una serie de autores y títulos que tienen en común el hecho de reflejar la experiencia vivida de su encuentro con el "Oriente»; en otras palabras, se trata de una serie de relatos de viaje. La literatura de este tipo, de gran calidad y cantidad en otros países como Francia o Gran Bretaña, no parece a primera vista tan abundante en nuestro país, donde se carece, desde luego, de una tradición tan continuada de "viajes a Oriente». La indudable vinculación de esta literatura con la expansión europea en este siglo explica la falta de atención a estos temas en una sociedad como la española, enfrentada a graves problemas internos y con escasa proyección al exterior ${ }^{4}$. Sin embargo, los relatos de viaje escritos por españoles sí conocen un notable crecimiento en

1 Entre los textos más recientes, cfr. CLIFFORD, James, «On Orientalism», en The Predicament of Culture, Harvard University Press, 1988; AHMaD, Aijaz, In Theory: Classes, Nations, Literatures, London, 1992, págs. 159-219 (agradezco a Ovidio Carbonell la referencia de estos trabajos); Lowe, Lisa, Critical Terrains: French and British Orientalisms, London, 1992. Entre las contribuciones en lengua francesa, aparecidas en los mismos antos que la obra de SAID, E., hay que señalar las de DJAlT, Hichem, L'Europe et l'Islam, Paris, 1978 y RoDINSON, Maxime, La fascination de l'Islam, Paris, 1980.

2 Véase, por ejemplo, GREGORY, Derek, «Between the book and the lamp: imaginative geographies of Egypt, 1849-50», Trans. Inst. Br. Geogr., 20 (1995), 29-57 (agradezco a Lluis Riudor el haber llamado mi atención sobre este texto).

3 Por ejemplo, LeCUYER, M. C. y SERRANo, C., La guerre d'Afrique et ses répercussions en Espagne, 1859-1904, Paris, 1976 y BACHOUD, Andrée, Los españoles ante las campañas de Marruecos. Madrid 1988. Cfr. los artículos reunidos por Morales LezCANo, V., en El colonialismo hispanofrancés en Marruecos (1898-1927) (Madrid, 1976), para una mejor comprensión de algunos de los aspectos históricos en que se sitúa esta producción.

4 A pesar de lo cual se pueden citar, entre otras, obras como las de MENTABERRY, Adolfo, Viaje a Oriente: De Madrid a Constantinopla, Madrid, 1893; ToDA, Eduardo, A través del Egipto, s. l., 1889 o RADA Y DELGADO, Juan de Dios, Viaje a Oriente de la fragata Arapiles, Barcelona, 1870-1882.

Hispania, LVI/I, núm. 192 (1996) 93-114 
lo que se refiere al Norte de África y más concretamente a Marruecos, que será, aun con todas las limitaciones y problemas que se conocen, el campo de expansión colonial de España a partir de la segunda mitad del s. XIX. La historia de esa expansión ha sido objeto de numerosos estudios y no voy a resumirla aquí; pero es, desde luego, el condicionante básico de los textos que quiero presentar y en ese sentido hay que tenerla en cuenta en todos ellos.

¿Quienes viajan a Marruecos? Entre los españoles, no abunda el tipo de viajero, tan común entre los ingleses o franceses que van a Egipto en esta misma época, y que está motivado principalmente por el deseo de conocer tierras exóticas. Bien es verdad que no es posible establecer un paralelo entre ambas situaciones y que la burguesía victoriana no tiene mucho que ver en gustos e intereses con la española de la misma época ${ }^{5}$. Lo que sí se da en España es el caso aislado del viajero que se traslada a Marruecos impulsado por el gusto de la aventura y de la acción y por el afán del descubrimiento de lo ignorado. La experiencia no siempre se traduce en un texto escrito y cuando ello sucede, lo hace de formas muy diversas. José María de Murga, uel Moro Vizcaíno" (1827-1876), no escribe un relato cronológicamente organizado de su vida en Marruecos, sino una serie de ensayos diversos sobre temas relacionados con el país, sin que tengan otra relación interna que la que les presta el objeto común de interés ${ }^{6}$. Murga, personaje original y hasta estrambótico, no parece haber querido proporcionar su experiencia personal de forma directa al hipotético lector; la reelabora y recompone, construyendo un texto nuevo en el que mezcla opiniones propias y documentación escrita por otros autores. Si el resultado no puede calificarse, en sentido estricto, como un "relato de viaje», sí que presenta uno de los aspectos que suelen resultar más definitorios en este tipo de textos: la experiencia cambiante de la identidad del viajero.

El impulso de la aventura y su transcripción lineal aparece también de forma evidente en el relato de Cristóbal Benítez, publicado por primera vez en 1880, en la Revista Contemporánea ${ }^{7}$. La propuesta de que acompañase en calidad de intérprete a la expedición de Oskar Lentz, que se proponía llegar hasta Timbuktu, le resultó aen extremo agradable, por el honor que me hacia de acompañar al sabio doctor alemán y porque iba a ver realizados los sueños de

5 Cfr. SATTIN, A., Lifting the veil: British Society in Egypt, London, 1988, especialmente pág. 125 y ss.

6 Murga, José María de, Recuerdos marroquies. Reimpreso con los apuntes de su segundo viaje y otros fragmentos publicados en 1877 por el Excmo. Sr. D. Cesáreo Fernández Duro, Madrid, 1906. La obra se publicó por vez primera en Bilbao, en 1868; en 1995 se ha publicado una edición facsimil. Cfr. Marín, Manuela, «The image of Morocco in three 19th century Spanish travellers», Quaderni di Studi Arabi, 10 (1992), 143-158.

? Aparece más tarde en el Boletin de la Sociedad Geográfica en 1886. He consultado la edición publicada en Tánger en 1899, bajo el título Mi viaje por el interior de África por Cristóbal Benitez, intérprete del consulado de España en Mogador. Sobre Benitez se sabe muy poco, como ya subrayó RicARD, R., Études hispano-africaines (Tetuán, 1956), pág. 188-89. Su actividad como intérprete en la embajada de José Diosdado se señala más abajo. 
mi infancia. ¡Recorrer el desierto de Sáhara! Esta idea me atraía como el imán atrae al acero, y hubiera renunciado cuantas ventajas me ofreció dicho doctor, por el solo placer de ir en su compañía y ser el primer español que iba a cruzar comarcas desconocidas de los europeos" ${ }^{8}$. Este tono de entusiasmo casi juvenil acompaña la descripción de su viaje, de narración viva y ágil, llena de incidencias, de peligros que acechan a sus héroes y de los que siempre consiguen salvarse.

En una hipotética tipología del viajero, Murga y Benítez deberían entrar en la categoría de aquéllos cuyo viaje sólo tiene por objetivo el traslado físico y mental de quien lo emprende; el viajero por el viaje en sí, en una palabra. Establecer esa tipología puede ser un ejercicio arriesgado, porque rara vez un viaje puede explicarse por una única motivación ${ }^{9}$. Resulta, sin embargo, bastante útil como método de interpretación y, en el caso de estos viajeros españoles, relativamente ajustada a la realidad tal como la presentan ellos mismos. De ahí que pueda decirse que, junto a estos "profesionales" del viaje que acabo de mencionar, existan otros cuyas profesiones, previas al hecho del viaje, son las que lo explican y determinan. Me refiero a los testimonios escritos por militares, embajadores o enviados diplomáticos, periodistas y científicos ${ }^{10}$.

A partir, sobre todo, de la guerra de 1859-60, la producción bibliográfica sobre Marruecos conoce una expansión enorme y una buena parte de esta producción está, precisamente, escrita por militares. Las revistas de ese carácter proliferan ${ }^{11}$ y mandos del Ejército de muy diversa graduación se lanzan a publicar sus impresiones, sobre todo de la guerra de Tetuán, pero también de otro tipo de estancias, breves o largas, en las que se adivina de forma más o menos evidente el interés por recoger información estratégica. Los «testigos» de la primera guerra de África abundan ${ }^{12}$, pero su retórica triunfalista tiene hoy día poco interés, a no ser que se revista del talento literario de Pedro Antonio de Alarcón, como veremos después. La guerra de 1860 abre otras posibilidades para los profesionales del ejército en los años que siguen a la expedición: son ellos quienes van a encargarse de reconocer el país, de

\footnotetext{
8 BENíteZ, C., Mi viaje, pág. 1-2.

9 Véase a este respecto VATIN, Jean-Claude, «Le Voyage: éléments pour une taxonomie», en $L a$ fuite en Egypte. Supplément aux voyages européens en Orient, Le Caire, 1989, págs. 9-41.

10 No incluyo a los misioneros en esta relación ya que su producción escrita no puede encuadrase dentro del género de "viajes», aunque por otro lado suponga un testimonio de gran interés sobre la apreciación e interpretación de la sociedad islámica en Marruecos. Véase a este respecto LOURIDO DíAZ, Ramón, "La iglesia española en el Magreb y sus aportaciones culturales», en MORALES LezCANo, Víctor (coord.), Presencia cultural de España en el Magreb (Madrid, 1993), 47-73.

II Cfr. HEADRICK, Daniel R., Ejército y política en España (1866-1898), Madrid, 1981, pág. 87.

12 Véase la bibliografía recogida por MiÉGe, J. L., Le Maroc et l'Europe (1830-1894), Paris, 1961, vol. I (Sources et bibliographie), con títulos como Pérez Calvo, Juan, Siete días en el campamento de África al lado del General Prim, Madrid, 1860 o LANDA, Nicasio, La campaña de Marruecos: Memorias de un médico militar ayudante que fue del cuartel general del ejército de África, Madrid, 1860.
}

Hispania, LVI/, núm. 192 (1996) 93-114 
transformarlo en texto geográfico y de elaborar, en suma, el mapa de los conocimientos disponibles sobre Marruecos ${ }^{13}$. La preparación profesional de los militares parece convertirlos en las personas más adecuadas para esta función, que entraña ciertos riesgos --más acusados en unas regiones y épocas que en otras-y que precisa de conocimientos especializados. A ello se une la facilidad de publicación en revistas y editoriales propias, dentro de un circuito relacionado estrechamente con las sociedades geográfico-coloniales y africanistas ${ }^{14}$. Los militares, exploradores y auténticos conocedores del mundo marroquí, se erigen así en sus expertos" e intérpretes indiscutibles, a la par que en actores y protagonistas del encuentro pre-colonial y colonial.

Entre esa abundante producción he seleccionado algunos nombres, significativos sobre todo de la diversidad de textos que es posible encontrar. Joaquín Gatell y Folch (1826-1879) ${ }^{15}$ es un militar sui generis, que se hace pasar como tal en la corte del sultán de Marruecos hasta conseguir ser nombrado comandante de su artillería. Los relatos de sus viajes y sus diarios están presididos, con todo, por el interés de llegar a un conocimiento exhaustivo del adversario en potencia. Como muchos de sus continuadores, Gatell se cuida de señalar con detalle el estado de las defensas costeras y del ejército marroquíes, llegando incluso a recomendar que la conquista del país se inicie por el Süs, a la que considera la región más conveniente para ello, puesto que "a más de las producciones naturales de que he hablado, que se podrían explotar con mucho lucro, nos haríamos duefios de un pueblo bastante numeroso, que en lo sucesivo nos sería muy útil» ${ }^{16}$.

Los primeros textos de Gatell se publicaron en 1862 y contenían, junto a informaciones de este tipo, otras de gran valor etnográfico ${ }^{17}$, en el contexto de una descripción de la expedición del sultán de Marruecos contra tribus rebeldes. Gatell aprovecha el desarrollo de los acontecimientos para dar información detallada sobre múltiples temas: tiendas de campaña y sus clases,

13 Esta labor adquiere un carácter institucional con la creación, en 1882, de la Comisión del Cuerpo de Estado Mayor para completar la cartografia marroquí, compuesta por el comandante Ramón Jáudenes y Álvarez y el capitán Eduardo Álvarez y Ardanuy. Cfr. GarCía Figueras, Tomás, La acción africana de España en torno al 98 (1860-1912), Vol. I, Madrid: C.S.I.C., 1966.

14 Entre otros, el caso de Emilio Bonelli es ejemplar a este respecto. Véase su conferencia Marruecos y Tánger, españoles, pronunciada en sesión pública de la Real Sociedad Geográfica el día 29 de marzo de 1920 y publicada en Madrid ese mismo año. Sobre la actuación anterior de Bonelli, v. García FIGUERAs, Tomás, «Espanoles en Africa en el siglo XIX», Miscelánea de Estudios Africanos, Larache, 1947, pág. 277-306. Acerca del papel de las sociedades geográficas en la expansión colonial en Africa, cfr. CAPEL, Horacio, «The Imperial Dream: Geography and the Spanish Empire in the Nineteenth Century", en GodLEwsk, Anne y SMith, Neil (eds.), Geography and Empire (Oxford, 1994), 58-73.

is MARí, Manuela, op. cit., págs. 144-45 y la bibliografía allí citada.

16 «Espedición (sic) al Sus, al Wad Nun y a Tekna emprendida en julio 1864 y terminada en marzo 1865 por D. Joaquín Gatell y Folchy, en BAUER LANDAUER, I., Papeles de mi archivo. Manuscritos (varios sobre Africa), Madrid, 1923, pág. 199.

17 Caro Baroja, J., utiliza a Gatell, sobre todo por sus informaciones sobre tribus del Sahara, en Estudios saharianos (Madrid, 1990), págs. 431-38. 
uniformes, ceremonias fúnebres, tipos de guardias en el campamento, ejecuciones, comida, reflexiones sobre el poder, sueldos, sistema penitenciario, papel de los $\breve{s u r a f a} \tilde{a}^{\prime}$, derecho de asilo, sistema de enseñanza, santos y milagros, caballos y armas en general, vestidos (da 17 nombres árabes de partes del vestido y el adorno de las mujeres) y un largo etcétera ${ }^{18}$. La pretensión de Gatell es abarcar por completo el mundo que observa en sus viajes, para lo cual había inventado un sistema de abreviaturas y señales que le permitía hacer rápidas anotaciones, al abrigo de la curiosidad de sus acompañantes; estas anotaciones le sirvieron luego de base para desarrollar el relato de sus expediciones. Nada queda fuera de su curiosidad, de la avidez de una mirada que registra la topografía de los paisajes de la misma manera que lo hace con la de los hombres que los habitan.

Esta pretensión enciclopédica se continúa en autores posteriores, que a menudo combinan cierta experiencia de estancias en Marruecos con lecturas de autores españoles y extranjeros. Sin el interés de la obra de Gatell, viajeroexplorador, aventurero y etnólogo involuntario, estas obras presentan la misma voluntad totalizadora, puesta por escrito con el designio evidente de la apropiación del territorio. En la espera de que ésta se lleve a la práctica, textos de ese carácter suponen una posesión intelectual del país que describen y que se presenta como presa fácil y perfectamente conocida. Un ejemplo -entre otros-: la Geografía militar de Marruecos ${ }^{19}$, del coronel de artillería Teodoro Bermúdez Reina, que se basa en notas tomadas durante su estancia como agregado militar en la Legación de Tánger. Su obra se inicia con una introducción sobre historia antigua (con el objeto de delimitar el origen de la raza marroquí), y se divide en cuatro capítulos: 1) situación geográfica, límites, cabos, cordilleras y ríos; 2) división regional y descripción de la población, con comentarios detallados sobre las tribus, su estado de sometimiento o rebeldía y su raza, así como descripciones de las ciudades y estudio de sus baterías artilleras; 3) resumen, con cuadros, de los dos capítulos anteriores y 4) itinerarios. El texto se completa con mapas de Tetuán, Tánger, Larache, Rabat-Salé y Mogador (al-Șawira), en los que se especifica la situación de las baterías. Es decir, de Gatell a Bermúdez Reina se ha dado un paso decisivo: los datos acumulados por el primero bajo la forma de diario de viaje se han convertido en conocimiento científico destinado al uso militar. La información se ha estructurado y clasificado, se ha transformado en una herramienta consciente de la voluntad de conquista. Lo que Gatell proponía desde su militarismo amateur alcanza, en esta y otras obras similares, categoría de libro de texto.

Otros dos autores pertenecientes al ejército español proporcionan una visión más personal, siempre dentro del mismo marco ideológico. El oficial

18 Su descripción del Sūs sigue el siguiente esquema: «Aspecto general del pais; recursos y productos naturales; clima, sanidad, población; ciudades; costas y puertos; costumbres y carácter de los habitantes; kabilas; gefes; disturbios ocurridos durante mi tránsito; reflexiones politico comerciales».

19 Barcelona: Publicaciones de la Biblioteca Militar [1894]. 
de ingenieros Julio Cervera Baviera, autor asimismo de una Geografía militar de Marruecos, publicó en Valencia en 1909 su Expedición al interior de Marrue$\cos$, que había escrito en $1884^{20}$. Con un evidente objetivo de reconocimiento militar ${ }^{21}$, el relato del viaje, sin embargo, se adapta más al modelo de «relato de aventuras", en las que el autor no tiene empacho en presentarse a sí mismo como el audaz explorador que escapa a peligros y asechanzas gracias a la variedad de sus recursos y a su valor y clarividencia. Su recorrido le lleva hasta $\mathrm{Fez}$ (límite de muchos de estos relatos de viaje) y le permite, de nuevo, hacer toda una serie de observaciones sobre las medidas que sería necesario tomar para una invasión del país, y a las que dedica el capítulo final de su obra ${ }^{22}$. Cervera, miembro destacado de los grupos de presión que actuaban en tal sentido en la política española, se muestra sin embargo partidario de intensificar los medios de penetración pacífica, «preparando el terreno para hacer prevalecer nuestros derechos a gobernar el imperio de los scherifes, derechos indiscutibles por razones históricas y geográficas». Hay, por tanto, que enviar oficiales y médicos, promover la enseñanza del español, establecer comunicaciones, fomentar el comercio...

Médicos militares sí residieron en Marruecos y alguno de ellos ha dejado constancia escrita de sus experiencias en el pafs, como Francisco Triviño Valdivia, coronel médico de la Sanidad militar, autor de varias obras entre las que señalaré Cinco años en Marruecos (1903) y Del Marruecos español, publicada en Melilla en 1920 y dividida en tres partes. La primera está dedicada a la desmembración del imperio marroquí y al estudio del Marruecos diplomático, político, judicial y pedagógico. La segunda contiene los siguientes epígrafes: España en Marruecos; nuestros derechos en Marruecos; necesidad absoluta de que España posea el Norte de Marruecos; el Marruecos español: fuentes de riqueza; del valor efectivo militar de los elementos indígenas; acción militar y política de España. En la tercera parte, Triviño reconstruye la vida en Marruecos antes del Protectorado y es aquí donde relata una serie de viajes por el norte del país, junto a sus impresiones sobre ciudades como Tánger, Larache, Arcila y Alcazarquivir. El recuerdo y reproducción de la vida anterior a la intervencion europea directa, situada en los primeros años del siglo xx (1903, 1904) se utiliza por tanto como colofón de los argumentos que justifican, a lo ojos del autor, la necesidad de la intervención. La mirada del viajero, que nunca es inocente, se reconstruye aquí desde un doble filtro, el del momento en que se registra y el otro, posterior, al que la perspectiva histórica de la nueva situación carga de significado premonitorio.

20 MaRín, M., op. cit., pág. 146.

21 Entre otros muchos pasajes similares, cfr. Expedición, pág. 35: «mientras mis servidores preparaban las viandas, yo me entretenia en examinar las condiciones inmejorables para establecer en aquel punto el campamento de un ejército expedicionario, por no faltar alli agua fresca, cristalina y abundante al par que forraje para el ganado y colinas circundantes para establecer puntos de observación y defensay.

22 Cervera, Julio, Expedición, págs. 136-40. 
Para terminar con la selección de autores militares, citaré uno más, que representa por sí solo uno de los aspectos más definitorios de las complejas relaciones entre España y Marruecos. En efecto, la presión hacia una intervención directa en el país vecino no debe hacer olvidar la presencia militar permanente de España en Ceuta y Melilla. Sobre todo, la serie de conflictos armados que se produce alrededor de Melilla y su peculiar situación dentro de la región del Rif la convertirán en uno de los ejes de la política española en relación con Marruecos, lo que a su vez generará una gran cantidad de textos escritos. El que deseo señalar aquí se debe al oficial de infanteria Teodoro Fernández de Cuevas (1872-1923) y se publicó en Melilla en 1907, con el título de Melilla: recuerdos de mi estancia en la plaza africana; cubre los primeros años (1902-1906) de la estancia de Fernández de Cuevas, destinado a la guarnición que poco después tuvo que enfrentarse a la campaña del Rif de $1909{ }^{23}$.

Perteneciente a una familia de militares involucrada en las últimas guerras coloniales de España, Fernández de Cuevas había nacido en La Habana y después de participar en la guerra de Cuba fue enviado a Melilla. La ciudad le produjo una impresión de "profunda tristeza, que se aumentó al visitar la población con sus calles empinadas, sus raquíticas casuchas y su aspecto de plaza sitiada, cuyo peso se siente sobre el corazón ... todo, todo se me venía encima, con la pesadumbre de una inmensa mole» ${ }^{24}$. Sin embargo, lo más interesante del texto de Fernández de Cuevas radica, no tanto en ésas y otras estampas de Melilla, sino en sus pequeñas excursiones por los alrededores de la ciudad, a las que le conduce su interés por descubrir los hábitos y formas de vida de los rifeños. De corto alcance, estos viajes le permiten no obstante asomarse a unas escenas ausentes por completo de la vida de guarnición. A veces, las completa con informaciones procedentes de otros militares que se internan también, cuando es posible, por el medio hostil que les rodea y que, precisamente por serlo, hay que conocer ${ }^{25}$. Curiosamente, este oficial tan enraizado, por razones familiares y de trayectoria personal, en la vida del ejercito, es, de todos los autores consultados, quien concede una atención menos sostenida a los aspectos militares de sus correrías por el Rif. Su punto de vista es el de quien ve proxima, aun con dificultades, la ocupación del territorio y la consiguiente alteración de las relaciones entre marroquíes y españoles. Desea, por tanto, fijar por escrito lo que ve para ese futuro no tan distante, y en el cual se pueda, gracias a su libro, "comparar la enorme diferencia que

23 La obra ha sido reeditada en Melilla en 1992, con una introducción sobre el autor y notas de F. SARO GANDARILLAS, dentro de un programa de reediciones de textos sobre la ciudad que promueve el Ayuntamiento de Melilla. A este mismo programa se debe la reedición del texto de Adolfo LLANOS ALCARAZ que citaré más adelante y que también lleva una introducción de F. SARo. Descontando la utilidad que tiene el facilitar un acceso más cómodo a obras de estas características, cabe preguntarse por la recepción que, en nuestros días, pueden tener textos de este tipo, escritos desde una óptica colonialista y en momentos de conflicto militar con la población del Rif.

24 Melilla, págs. 53 y 55.

25 Las páginas 113-135 están dedicadas a reconstruir el viaje del teniente coronel Venancio Álvarez de Cabrera y el capitán Pablo Cogolludo García desde Melilla a Wuŷda, en 1905.

Hispania, LVI1, núm. 192 (1996) 93-1 14 
existe entre la sensación sentida ante un país explorado y familiar y la sensación atractiva y misteriosa producida por ese mismo país, habitado por tribus casi salvajes y la entrada en el cual nos está prohibida» ${ }^{26}$. Se trata del mismo recurso utilizado por Triviño, pero en sentido inverso; donde aquél proyectaba su recuerdo hacia el pasado, con el objeto de resaltar la benéfica obra colonizadora, Fernández de Cuevas elabora una foto-testigo del presente que pueda servir de contraste en los tiempos por venir.

Las relaciones diplomáticas entre España y Marruecos produjeron, en la época que nos ocupa, una serie de textos de diverso interés, en especial los relacionados con las embajadas enviadas a la corte del sultán en Marrakech o en Fez. De la primera de ellas, encabezada por Francisco Merry y Colom, se conserva la Relación del viaje a la ciudad de Mamuecos, que por disposición del Excmo. Sr. D. Manuel Pando, marqués de Miraflores, primer secretario de estado, verificó en el mes de mayo de l863 d. Francisco Merry y Colom, ministro residente de S.M. La reina de España cerca del sultan Sidi Mohammed ben Abderrahman, editada por la Imprenta Nacional en Madrid en 1864. La introducción subraya que se trata de la primera embajada enviada a Marruecos desde tiempos de Carlos III.

Texto seco, distante, apegado a los hechos más inmediatos y con escasísimas notas personales, esta Relación tan característica del estilo de «despacho diplomático» marca, sin embargo, una serie de pautas reconocibles en otros textos posteriores del mismo género. La Relación de Merry establece el itinerario geográfico que seguirán embajadas posteriores, con un viaje por mar desde Tánger a Mogador y un posterior traslado desde la costa hasta Marrakech. El ritmo del viaje lo marcan el paso de la caravana y las condiciones climatológicas, la instalación del campamento y su retirada, los contactos esporádicos con la población local. La llegada a Marrakech supone un día de espera para organizar la entrada oficial en la ciudad, seguida de la estancia en la Ma'müniya, la entrevista oficial con el sultán y los banquetes de despedida. Todo ello es descrito minuciosamente, con un énfasis especial en los aspectos ceremoniales y en el carácter de "representación" del poder que tienen los contactos, puramente formales, entre el enviado español y los gobernantes marroquíes. La audiencia del sultán, al aire libre, se describe como una función teatral, en la que los actores recitan sus partes conforme al guión establecido de antemano. Y ese mismo esquema, con las acotaciones necesarias para componer el escenario (las tribus que traen la müna cuando la caravana atraviesa su territorio, el calor y las incomodidades del viaje, el despliegue del fasto ceremonial, los banquetes a estilo marroqui) se mantiene y repite en los textos posteriores, a manera de trama sobre la que se urden, a veces, relatos más personales en la apreciación del país y sus gentes. Merry hace gala de una notable falta de receptividad ante el exotismo que tanto llama la atención, como veremos luego, de otros contemporáneos suyos: «La legación - afirmavisitó las cercanías de Marruecos [Marrakech] y la ciudad, cuyo interior nada

25 Melilla, pág. 42. 
de curioso ofrece» ${ }^{27}$. Pero la sequedad misma de su discurso, la relación des. nuda del itinerario y los incidentes del camino tienen un significado evidente: no es necesario describir lo que no existe, lo que no tiene relevancia alguna para la mirada del observador, embebido en sí mismo y su misión de representante del poder extranjero. Siendo en apariencia un "relato de viaje», organizado en forma lineal a lo largo de un itinerario, la Relación de Merry y Colom se limita voluntariamente a levantar acta de un traslado físico, el único aspecto del viaje del que su autor considera necesario dejar constancia.

Un aspecto interesante de ésta y posteriores embajadas es su composición. A Merry le acompañaba un pequeño grupo, compuesto por dos diplomáticos, el cónsul español en Tánger, Felipe Rizzo, que oficiaba también como intérprete, un médico militar, un misionero ("para prestar a la Legación los auxilios espirituales»), dos marroquíes (un intérprete y un escribano) y el pintor sevillano Joaquín de Bécquer, «quien por propia iniciativa y sin más estímulo que su amor al arte, habŕa deseado vivamente visitar el interior de Marruecos" ${ }^{28}$. Entre este grupo de acompañantes del embajador se encuentran, en ocasiones posteriores, otros relatores del viaje que introducen, en el esquema obligado, una visión que va más allá del mero registro de los hechos.

En 1882, el embajador enviado a Marrakech era José Diosdado Castillo. Formaban su séquito el primer secretario de la Legación española Wenceslao Ramírez de Villa-Urrutia; dos militares ya mencionados, Jáudenes y Alvarez Ardanuy; el franciscano José Lerchundi (1836-1896) ${ }^{29}$, en su doble capacidad de sacerdote e intérprete de árabe; Cristóbal Benítez, también intérprete y que ya había publicado, como se ha visto antes, su relación de viaje al interior de África, y el médico militar José Santana Nestosa. Fue Villa-Urrutia quien, en 1883, publicó en Madrid un testimonio de esta expedición, bajo el título Una embajada a Marruecos en 1882: Apuntes de viaje ${ }^{30}$.

La pretensión de Villa-Urrutia es doble: por un lado, la evidente de dejar por escrito sus impresiones de viaje; por otro, luchar contra la creciente bibliografía sobre Marruecos, en la que abunda kel español que, sabiendo leer y escribir, visita, aun sin salir de Tánger, el imperio de Marruecos [y] se considera en el deber de conciencia de hacer partícipes de sus impresiones a todos sus compatriotas, para que éstos y el Gobierno sepan a qué atenerse respecto de un país en el que tiene o debe tener España fija su mirada como el águila en el ave que ha de hacer su presa» ${ }^{31}$. Por tanto, pretensión de autenticidad, de conocimiento directo, de testimonio sobre lo que pocos han tenido

27 Relación, pág. 57.

28 Relación, pág. 25. La edición del texto va acompañada, en efecto, de una serie de litografías sobre dibujos de Bécquer. Lleva además una "vista general de la ciudad de Marruecos», obra también de Bécquer, y un plano de la ciudad.

29 Cfr. RiCARD, R., Études hispano-africaines, pág. 186-87 y FERNẢNDEZ RoDRíguEZ, M., España y Marruecos en los primeros años de la Restauración (1975-1894) (Madrid, 1985), págs. 190-94.

30 He utilizado la reimpresión de Ceuta, 1991.

31 Una Embajada a Marruecos, pág. 33.

Hispania, LVI/, núm. 192 (1996) 93-114 
UN ENCUENTRO COLONIAL: VIAJEROS ESPAÑOLES EN MARRUECOS (1860-1912) 10

oportunidad de ver y conocer. $\mathrm{Y}$ además, conciencia de instalarse en lo que su autor llama el «espíritu altamente patriótico que desde la guerra de África informa toda nuestra literatura marroquín ${ }^{32}$. Del mismo modo que los militares tratan de acotar la realidad marroquí, de encerrarla en los límites de los mapas y los textos que escriben para poder dominarla, los diplomáticos utilizan su vía de penetración, el camino de Marrakech, como forma privilegiada de acceso al conocimiento.

De la embajada del general Martínez Campos en 1893 dejó constancia, entre otros, el periodista José Boada y Romeu, en un texto al que me referiré más adelante ${ }^{33}$. Pero sin duda el relato más completo y que mejor representa el papel del diplomático/viajero es el compuesto por Rafael Mitjana Gordón (1869-1921): En el Magreb-el-Aksa: Viaje a Marruecos (Valencia, 1905). Mitjana, entonces excedente (por haberse suprimido su puesto en una reforma administrativa de la carrera diplomática), había sido secretario de la Legación en Tánger, y consiguió agregarse a la embajada que en 1900 presidió Emilio de Ojeda ${ }^{34}$, para realizar, así, "uno de los mayores deseos de mi vidan, el de visitar «un país tan extraño como desconocido, tan interesante como curioso, en el extremo Occidente de los orientales, en el Magreb-el-Aksa de las mil y una noches: ${ }^{35}$.

Mitjana sólo pretendía, dice en su introducción, escribir un diario de su viaje. Nada, pues, en apariencia, de fervor patriótico; su única motivación aparente es la curiosidad del viajero. Pero sin escapar al marco de connotaciones ideológicas que he venido señalando, lo ensancha hacia un repertorio de recursos retóricos que lo convierten en paradigma de visión "orientalística» del mundo observado. La frase con la que termina su introducción, y que acabo de citar, es reveladora a este respecto: el viajero parte hacia el interior de Marruecos desde un contexto de lecturas y saberes previos que le hacen anhelar la inmersión en el esplendor de lo desconocido. Mitjana, conocido sobre todo por su labor posterior como musicólogo (fue, como es sabido, el descubridor y editor del Cancionero de Uppsala, además de publicar otros muchos trabajos sobre historia de la música española) es un hombre de amplia cultura, que prepara su viaje concienzudamente y pretende que el lector le siga por ese camino. Antes de la descripción de Marrakech, dedica por tanto una larga digresión a la historia de Marruecos desde los almorávides, extraída del $K$ al-Istiqșā' de al-Nāșirī (m. 1897), para lo que cuenta con la ayuda de Reginaldo Ruiz; autor y lector, convenientemente preparados,

\footnotetext{
32 Ibidem, pág. 34

33 Sobre esta embajada, cfr. FERNÁNDEZ RoDRíGUEZ, M., España y Marruecos en los primeros años de la Restauración, pág. 289.

34 Los componentes de la embajada siguen el esquema ya visto en otras ocasiones: militares (el capitán Ayensa y, de nuevo, Álvarez Ardanuy; Jáudenes había muerto en 1883), diplomáticos (Mitjana y Jaime de Ojeda, hijo del embajador); religiosos (los franciscanos Pascual Cervera y Domingo García); médicos (Alfonso Cerdeyra) e intérpretes (Manuel Saavedra y Reginaldo Ruiz). Como muestra de la evolución de los tiempos, acompañaban también al embajador su mujer y su hija.

35 En el Magreb, pág. VIII.
} 
pueden después adentrarse por las calles de la ciudad. Historia leída y descripción vivida acompañan de continuo el relato, en cuyas notas a pie de página se citan textos árabes traducidos (como el Corán o el Rawd al-qirțās) viajeros españoles (Luis del Mármol, Fray Ginés de Ocaña, Domingo Badía, José María de Murga) misioneros (Francisco de San Juan del Puerto) o trabajos de erudición como los de Brockelmann.

En la estela de las expediciones militares o las embajadas extraordinarias, la prensa española del s. XIX y comienzos del s. XX envía numerosos corresponsales a Marruecos. El interés creciente por los asuntos de África se refleja en la aparición regular de artículos periodísticos ${ }^{36}$, pero también en relatos de viaje que recogen experiencias directas o reúnen crónicas enviadas y ya publicadas con antelación. La guerra de 1859-60 contó con dos cronistas de excepción, Gaspar Núnez de Arce (Recuerdos de la campaña de Africa, Madrid, 1860) y Pedro Antonio de Alarcón, cuyo Diario de un testigo de la guerra de África gozó de una gran popularidad y se ha ido reeditando de forma continua hasta nuestros días ${ }^{37}$. Los diversos enfrentamientos militares en torno a Melilla también produjeron relatos periodísticos, centrados sobre todo en el desarrollo de las operaciones, como las que dedicaron José Boada y Adolfo Llanos a la campaña de 1893-94 ${ }^{38}$; son sólo algunos de los muchos ejemplos que podrían darse. Estos corresponsales de guerra, como otros periodistas que viajan en tiempos más pacíficos a Marruecos, tienen en común su profunda implicación con la acción expansionista española. Alarcón se había alistado como soldado de la expedición militar que llegaría a tomar Tetuán; Llanos había sido militar de carrera; Boada hizo uno de sus viajes en compañía de Carlos Godó, "uno de los fabricantes más renombrados de Cataluña, hombre emprendedor como pocos, y que sólo guiado por el deseo de abrir nuevos mercados a las manufacturas españolas, no vacilaba, a pesar de su edad algo avanzada, en sufrir las molestias consiguientes en un viaje de esta índole" ${ }^{39}$. Otros, como Alfonso Jara, acompañan a un político (en este caso, Canalejas), en un breve viaje al norte de África ${ }^{40}$. Alguno de los autores ya citados, como Triviño Valdivia, médico militar, era también periodista; es en esta categoría profesional donde es más difícil deslindar intereses o vocabularios

36 Cfr. LECUYER, M. C. y SERRANO, C., La guerre d'Afrique et ses répercussions en Espagne, 1859-1904, Paris, 1976. Revistas como La llustración Artística o La Ilustración Española y Americana han sido explotadas por autores como LITVAK, Lily, en El sendero del tigre: exotismo en la literatura española de finales del siglo XIX 1880-1913, Madrid, 1986 (capítulo II: «El jardín de Alah. Exotismo musulmány)).

${ }^{37}$ La edición que he utilizado (Madrid, 1923) es la novena. La primera edición, de 1859, va profusamente ilustrada «con vistas de batallas, de ciudades y paisajes, tipos, trajes y monumentos, con el retrato del autor y de los principales personajes, copiados de fotografias y croquis ejecutados en el mismo teatro de la guerra), según reza la portada.

38 BOADA Y ROMEU, José, «La campaña de Melilla», en Allende el Estrecho, Barcelona, 1895; Llanos Alcaraz, Adolfo, La campaña de Melilla de 1893-1894, Madrid, 1894.

39 BOADA, José, Allende el Estrecho, pág. 58.

40 De Madrid a Tetuán, Madrid, 1903. 
UN ENCUENTRO COLONIAL: VIAJEROS ESPANOLES EN MARRUECOS (1860-1912) 105

comunes, más allá de la retórica «imperialista" que se manifiesta, por otro lado, de formas muy diversas. La grandilocuencia de Alarcón (su Diario debe de ser la obra literaria escrita en español con mayor número de signos de admiración por página) está muy lejos del estilo de Boada, pero ambos comparten una serie de elementos básicos de apreciación de la sociedad marroquí, condicionados en su expresión por sus diferentes personalidades y talentos y por las circunstancias de su encuentro con esa sociedad. Si ha de buscarse, entre estos y otros periodistas, una motivación común, es la muy evidente de dirigirse a la opinión pública española desde opciones ideológicas y políticas muy definidas ${ }^{4 i}$ y con la pretensión de intervenir activamente en la formación de esa opinión.

Terminaré este resumen tipológico de los viajeros españoles a Marruecos con una breve referencia a los que he catalogado como "científicos" y entre los que hay que contar a naturalistas como Fernando Amor ${ }^{42}$, etnógrafos como Constancio Bernaldo de Quirós ${ }^{43}$, o médicos como Felipe Ovilo y Canales ${ }^{44}$. El volumen de la producción en este campo no puede compararse a la que se lleva a cabo en otros países europeos ${ }^{45}$ aunque se inscriba en idénticos presupuestos ideológicos: la catalogación y clasificación de todo tipo de informaciones referentes al mundo ajeno que se explora y que de ese modo abandona su caos original para transformarse en materia de estudio y por tanto en objeto de dominio. Por su parte, los científicos más directamente relacionados, por su especialización profesional, con una sociedad islámica como la marroqui -es decir, los arabistas- muestran a finales del siglo xIX una

41 Entre las que hay que señalar el radicalismo de Rodrigo Soriano, que publicó en 1894 Moros y cristianos: notas de viaje (cfr. BACHOUD, A., Españoles, pág. 262). El novelista Isaac Mufioz publicó crónicas en El Heraldo de Madrid entre 1911 y 1912, aunque es más recordado por su obra literaria (cfr. BACHOUD, A., op. cit., pág. 328 y LiTVAK, L., El sendero del tigre, que hace un uso abundante de su novela Un héroe del Mogreb).

${ }^{42}$ Recuendos de un viaje a Marruecos, Sevilla, 1859. Véase también MuÑoz Calvo, Sagrario, «Naturalistas españoles en el noroeste de Aftica (1850-1930): descubrimiento de la flora marroquí e interés por los recursos naturales», Awräq, anejo al vol. XI (1990), 194-211.

43 Su trabajo se publicó en la obra colectiva Yebala y el bajo Lucus. Expedición de abril-junio de 1913, Madrid, 1914; Bernaldo de Quirós firma también el Diario de viaje de la expedición, promovida por la Real Sociedad Española de Historia Natural. La obra contiene también los estudios de FernÁNDEZ NAVARRo, Lucas, "Geografia física y geología de la región»; DANTín CERECEDA, Juan, "Vegetación y agricultura» y CABRERA LATORRE, Angel, "Zoologia».

44 Ovilo fue director de la Escuela de Medicina española de Tánger y autor de obras como $\mathrm{La}$ mujer marroquí: estudio social (Madrid, 1886), que no es un relato de viajes. Sobre Ovilo véase MARTíneZ MonTÁVEZ, Pedro, "Sobre el aún "desconocido" arabismo espafiol del siglo XIX", Ensayos marginales de arabismo (Madrid, 1977), 3-22 y la apreciación de José BOADA sobre su actividad en Allende el Estrecho, pág. 25 y ss.

45 Véase, a título de ejemplo, RIVET, D., «Exotisme et «pénétration scientifique»: l'effort de découverte du Maroc par les français au début du xx ${ }^{\mathfrak{e}}$ siècle», en Connaissances du Maghreb. Sciences sociales et colonisation (Paris, 1984) págs. 95-109 y HeFFERMAN, Michael J., "The Science of Empire: The French Geographical Movement and the Forms of French Imperialism, 1870-1920 m, en GodLEwSKA, Anne y SMTTH, Neil, Geography and Empire (Oxford, 1994) 92-114. 
interesante ambivalencia respecto a ella. No existen relatos de viaje escritos por arabistas, por la sencilla razón de que viajaron a Marruecos en muy contadas ocasiones y, cuando lo hicieron, su interés exclusivo por la adquisición de manuscritos árabes apenas produjo algún artículo como el de Francisco Codera ${ }^{46}$ sobre el viaje de Julián Ribera, agregado a la embajada de Martínez Campos y cuya misión tuvo muy poco éxito. L.os arabistas españoles, en pleno proceso de consolidación y legitimización de su disciplina dentro de las ciencias históricas y filológicas del momento, se interesaron muy escasamente por la realidad contemporánea de Marruecos, que dejaron en manos de los "africanistas", es decir, aquéllos cuya actividad coincidía en gran parte con la de los viajeros que se han ido viendo hasta aqui y que estaban en buena medida al margen de la ciencia oficial y universitaria ${ }^{47}$.

En la abundante literatura sobre Marruecos en esta época, los relatos de viaje suponen un acercamiento directo a la realidad que se desea conocer. El viajero, al trasladar al papel su experiencia, hace partícipe al lector del testimonio de un descubrimiento, de un itinerario tanto geográfico como personal. De ahí su atractivo para el público potencial del momento, que será siempre más amplio que el de los lectores de círculos especializados, a los que se dirigen informes, textos históricos, compilaciones cartográficas, etc.. El relato de viaje es por tanto, junto a la crónica periodística, el medio privilegiado de penetración en la opinión pública. El uso de la primera persona que conduce la narración establece una comunicación directa, una complicidad con el lector a quien se ofrece la «realidad» en vivo, la experiencia sobre el terreno. De hecho, es ésta una de las constantes que aparecen en los prólogos o introducciones a los relatos: la pretensión de ofrecer un documento verídico, que por serlo tiene más valor que otros textos de mayor ambición aparente.

Los relatos de viaje ofrecen además un retrato de la identidad de su autor tal cómo éste desea verla proyectada en su texto. Ante el lector se presenta una imagen inalterable de espectador que juzga lo observado desde una posición de superioridad intelectual, pero a veces se observa cómo esa identidad inicial se ve afectada por el desarrollo del viaje y su exposición a otra realidad cultural. A menudo el recurso básico para mantener intacta la propia identidad es el rechazo frontal a la del otro observado, que se agudiza tanto más cuanto que ese otro se percibe como adversario, potencial o real: el caso extremo lo presentan muchos relatos de militares, para quienes ese otro es simplemente

46 "Libros procedentes de Marruecos», B.R.A.H., XXIV (1894), 365-78. Véase también CODERA, Francisco, Discurso de contestación al de ingreso de Julián Ribera en la Academia de la Historia, Madrid, 1915. De su viaje por otros paises del Mágreb dejó escrito un diario el también arabista Francisco PONS BoIGUEs, publicado primero en la Revista Contemporánea (1888) y reeditado en Estudios breves (Tetuán, 1952).

47 Sólo Julián RIBERA se interesó por la necesaria formación de especialistas en asuntos marroquies; cfr. LóPEZ GARCiA, Bernabé, «Julián Ribera y su «taller» de arabistas: una propuesta de renovación», M.EA.H., XXXII-XXXIII (1983-84), 111-128. Véase también MoRAlES LEZCANo, V., Africanismo y orientalismo español en el siglo XIX, Madrid, 1988.

Hispania, LVI], núm. 192 (1996) 93-114 
el enemigo y como tal debe ser descrito ${ }^{48}$. No pretendo aquí sino apuntar el interés de este tema, como uno de los posibles niveles de análisis de los textos en cuestión; habría que añadir aún otro más, el de su valor documental -histórico y antropológico-, desigual según los distintos autores pero cuyo conjunto representa una aportación importante para el conocimiento de algunos aspectos de la sociedad marroquí.

Al referirme a la tipología de los viajeros españoles, he subrayado en varias ocasiones una de sus características más llamativas: su vinculación más o menos expresa a los proyectos de expansión colonial. En ese sentido hay que interpretar su voluntad de manipular y dominar el mundo que se observa y su intención de ampliar al máximo los datos que sobre él se poseen. El país y sus habitantes son catalogados, definidos, clasificados, y todo ello se hace en el marco de un pensamiento claramente colonial. El que la capacidad real de España para embarcarse en la construcción de un nuevo imperio colonial fuera muy relativa ${ }^{49}$ no impidió el desarrollo de un lenguaje y unos conceptos estrechamente emparentados con los que se utilizaban en otros países europeos con mayores posibilidades de expansión territorial. Dedicaré la última parte de este trabajo al análisis de algunos de los elementos de ese lenguaje empleados por los viajeros españoles.

El horizonte de la gran mayoría de estos relatos es doble. Por un lado, la realidad que se contempla; por otro, la presencia de España. Y no es sólo que se compare lo que se ve con lo que se ha dejado atrás, ademán casi inconsciente de cualquier viajero por tierras extrañas, sino que el objeto observado --el país y sus habitantes- se apercibe como terreno de intervención, ya sea pacífica o militar. El primer argumento que se emplea en este sentido es el del atraso: agricultura, comercio o industria no existen o sobreviven en condiciones miserables. No hay instituciones y el sistema político está presidido por el despotismo ${ }^{50}$. La mitología del progreso, de la modernización imprescindible de las sociedades humanas, juega un papel determinante en la construcción de la ideología colonial y los viajeros españoles - que proceden de un país que ofrece reflexiones similares a quienes lo visitan- asumen felizmente el estandarte de la modernidad para anular las formas de vida que contemplan ${ }^{51}$. Marruecos debe entrar en la senda del progreso y para ello debe ser colonizado, porque sólo así conseguirá desprenderse de un atraso secular. Alarcón

48 «No hay más que un medio de hacerse respetar de tribus de raza Tamazirt (...) en primer lugar la persuasión y si ésta no produce resultado, el extermino y el terror, toda otra conducta se interpreta por estos bárbaros como señal de debilidad y con el débil a todo se atrevenus (BERMúdez REINA, Teodoro, Geografia de Marruecos, pág. 215).

49 Morales LEzCANo, Víctor, El colonialismo hispanofrancés, pág. 47 y ss., sobre las implicaciones económicas de la penetración española en Marruecos.

50 Cfr. GrosRichard, Alain, Structure du sérail. La fiction du despotisme asiatique dans l'Occident classique, Paris, 1979.

51 Véanse los temas, muy semejantes, de la literatura anglosajona de viajes por Sudamérica en el s. XIX, analizados por PRATT, Mary Louise, Imperial Eyes: Travel writing and transculturation (London, 1992), pág. 151 y ss. 
alcanza alturas casi líricas al describir la actividad de los ocupantes de Tetuán:

"Quiero que en futuros tiempos, cuando este país despierte de su mortal letargo; cuando entre en la comunión de los pueblos; cuando aprecie y ame ya todo lo que hoy aborrece o desconoce; cuando sea, en fin, una nación culta, civilizada, cristiana, amiga de la Humanidad, se diga por la raza que lo habite que en el año de 1860 pasó por aquí un Ejército de Españoles, y que este Ejército, no sólo tendió los hilos eléctricos y las vías férreas sobre las llanuras de Guad-el-Jelú, y surcó las olas de este río con barcos de vapor, sino que imprimió un periódico dentro de los muros de Tetuán" ${ }^{52}$.

Este proceso de modernización, identificado con la adopción de la técnica y la cultura occidentales, produce en muchos viajeros unas reflexiones paradójicas. Por un lado se insiste en la necesidad de ese proceso, entre otras cosas como argumento fundamental de la intervención exterior; por otro, se lamentan sus consecuencias e incluso se ridiculizan sus signos externos ${ }^{53}$. Murga, entre otros, censura la afición de los habitantes acomodados de las ciudades por ciertas manufacturas occidentales (relojes de pared, cajas de música, espejos) ${ }^{54}$, sin plantearse en momento alguno que la penetración económica europea está arruinando, durante este siglo, las industrias marroquíes tradicionales ${ }^{55}$. Como otros autores, Murga desea un imposible: que la introducción del progreso no afecte a las formas de vida que suponen el mayor atractivo para el viajero. Villa-Urrutia también se lamenta de la pérdida de exotismo del ejército marroqui: «la uniformidad le ha hecho perder mucho bajo el aspecto artístico, despojando al soldado de su incómodo pero elegantísimo ropaje talar y de sus características armas, la corva y plateada gumía y la espingarda de bizarra hechura y desmedido tamañon, y compara desfavorablemente a la población de Tánger, demasiado influída por los usos y modas de la colonia europea, con la de Marrakech, donde «el marroquí se nos presenta tal como es, y no tal como el europeo le ha hecho sers ${ }^{56}$.

Con todo, el impulso viajero de estos autores no se explica únicamente por su identificación exclusiva con la ideología colonial en tanto que expansionismo territorial. Otros elementos -que forman parte de ese mismo esquema ideológico-- definen y explican su voluntad de traslado a un mundo ajeno. Acabo de señalar uno de ellos: la búsqueda de formas de vida exóticas y misteriosas. En común con muchos otros viajeros occidentales, los españoles que

52 Diario, II, pág. 234. Cfr. también I, 326 y II, 233.

53 Cfr. SPURR, David, The Rhetoric of Empire: Colonial Discourse in Journalism, Travel Writing, and Imperial Administration, Durham/London, 1993, pág. 76 y ss.

54 Recuerdos marroquies, pág. 170.

55 Véase ABU-LugHoD, Janet, Rabat: Urban Apartheid in Morocco (Princeton, 1980), pág. 75-92.

56 Embajada, pág. 49 y 53. BoADA (Allende el Estrecho, pág. 17) afirma, al referirse a las mujeres judías de Tánger, que «visten casi todas a la europea, con lo cual pierden para el viajero la mayor parte de su encantos.

Hispania, LVII, sim. 192 (1996) 93-114 
van a Marruecos encuentran allí un espacio soñado, una geografía imaginaria en la que se cumplen expectativas alimentadas por la anticipación literaria: «iEra el espectáculo soñado por todos los que han divertido su fantasía con héroes orientales! ${ }^{57}$. Calles, zocos, aduares y caminos adquieren un significado especial: son cuadros llenos de pintoresquismo, habitados por representaciones del teatro de lo exótico, lo inhabitual, lo extraordinario. Los viajeros de esta época tratan de fijar por escrito, en detalladas descripciones, el bullicio del mercado, las evoluciones de la caballería, o la venta de esclavos, con la intención de recuperar esas escenas de un modo casi fotográfico. El "cuadro" se repite de un relato a otro, con ligeras variaciones en las pinceladas y la técnica del color.

En paralelo a la atracción del exotismo, el viajero siente a veces la tentación de sumergirse en un modo de vida que le ofrece posibilidades desconocidas en su sociedad de origen. Esta tentación sólo se presenta a quienes han experimentado, antes de su viaje, un proceso de desencanto con la "rutina" y la mediocridad de la civilización occidental. El atractivo de la ruptura con esas condiciones de vida y la llamada de un mundo liberado de reglas y opresiones sociales se identifica, usualmente, con los grandes espacios desérticos habitados por nómadas nobles y salvajes. De todos los viajeros que he señalado, es Murga quien más claramente sucumbe a la idealización de los árabes marroquíes, a quienes contrapone muy favorablemente con los degradados habitantes de las ciudades ${ }^{58}$. También en Mitjana asoma, a veces, una reflexión de este tipo: «Él, después de nuestra partida, emprenderá de nuevo la marcha por el desierto, sin necesidades, ni trabas, libre, independiente, durmiendo bajo la tienda y soñando a su capricho. Es probable que sea él quien encuentre primero la felicidad" 59 .

Los motivos que empujan al viajero a la búsqueda de lo exótico, ya sea en un contexto urbano o en el de los grandes espacios vacíos, varían de acuerdo con su personalidad. En todo caso se trata de un paréntesis limitado en el tiempo de sus vidas, pero que satisface el ansia de huida de lo cotidiano y, más importante aún, la necesidad de la penetración en el misterio. Aunque paulatinamente abierta a la curiosidad del extranjero, la sociedad marroquí mantiene un carácter de coto cerrado, de espacio prohibido, que es uno de los componentes mayores de su atractivo. Inmediatamente antes de su entrada en Tetuán, Alarcón declara: «Yo quiero ver la población, las costumbres, los trajes, los ritos, las fisonomías de los Moros. Quiero hablarles; ser amigo de ellos; penetrar en el fondo de su alma; sorprender el misterio de su extraña vidas ${ }^{60}$. Ya hemos visto antes cómo Fernández de Cuevas, en el

57 AlarCón, P. A., Diario, pág. 95.

58 Recuerdos, pág. 180 y ss.

59 En el Magreb-el-Aksa, pág. 297; v. también pág. 222. Cfr. SPURR, op. cit., pág. 129 y ss.

60 Diario, II, pág. 29. Compárese con su actitud al poco de llegar a la costa marroquí: «Lo indudable, en fin, es que en el Boquete de Anguera está la callada esfirge, depositaria del enigma de la verdadera Africa, del Africa misteriosa e independiente, que empieza en él y no en las costas̀ (1, pág. 47). 
prólogo a su libro, expresa su intención de registrar la vida en el Rif, país misterioso y vedado a los españoles. Ese deseo de conocer lo oculto se traduce a menudo en las visitas a casas marroquíes, escena-tipo que se repite una y otra vez ${ }^{61} \mathrm{y}$ en la que el viajero pone todas sus esperanzas de intromisión en los secretos de la vida cotidiana. El desplazamiento físico hacia la casa se produce con frecuencia en una situación de desorientación: el guía avanza por callejuelas oscuras y laberínticas, flanqueadas por muros altos y sin ventanas. Falto de referencias, perdido en un espacio sin señales reconocibles, el viajero desemboca de súbito en la casa a donde ha sido invitado, clave de todos los misterios.

Como todos estos viajeros son hombres, el más esquivo de los secretos marroquíes - sus mujeres- sigue eludiéndoles aun dentro de la casa. De ahí la elaboración de toda una serie de estrategias para superar este último y más infranqueable de los obstáculos a que se enfrenta el viajero; desde las literarias - la construcción de una imagen de las mujeres marroquíes que perdura hasta nuestros días- hasta tretas y argucias para arrancar, desde una azotea o desde detrás de una cortina, contemplaciones furtivas y siempre insatisfactorias ${ }^{62}$. Los viajeros deben contentarse con conocer y tratar a mujeres judías, como las señoritas de Nahón que encuentra Alfonso Jara en Tánger, «ambas esbeltas, inteligentes, ilustradas y amabilísimasn; tanto, que dejan por un momento sus trajes europeos para vestir el atuendo tradicional y satisfacer el interés de los visitantes por el color local ${ }^{63}$. Pero las mujeres musulmanas siguen fuera del alcance de la mirada ajena, lo que en buena parte explica la gran atención que les dedican los viajeros y la magnificación de cualquier incidente, por pequeño que sea, en que se produzca un encuentro con ellas.

Mucho de lo que escriben estos viajeros está dedicado a la descripción de paisajes y cuadros de conjunto. Sin embargo, no están aislados de la población y muchos muestran, como Alarcón, un interés decidido por relacionarse con marroquíes. Debido a las circunstancias de cada viajero, condicionadas por su profesión, la red de contactos que se establece puede ir desde los ministros del sultán hasta guías de caravanas, comerciantes, jefes tribales, etc. Las relaciones más estables son las que unen al viajero con su intérprete (ninguno conoce las lenguas habladas en Marruecos) o su informador, que suele pertenecer a la minoría judía o tener alguna relación profesional con el ejército o el comercio españoles. Se trata, siempre, de unas relaciones peculiares, definidas por su instrumentalidad y su asimetría. Un ejemplo de la jerarquización de estas relaciones es el de Muhammad, informador privilegiado de Fernández de Cuevas, que le somete a una serie de pruebas para confirmar su honradez en materia monetaria; por su parte, gracias a Muhammad, el viajero contempla aceremonias y costumbres curiosas, no presenciadas en estos campos por muchos europeos", es invitado a su casa y conoce a su mujer, Fáțima

61 Por ejemplo, Cervera, Expedición, pág. 17 y ss. y BOADA, Allende el Estrecho, pág. 114-118.

62 BOADA, Allende el Estrecho, pág. 119-120.

63 JARA, A., De Madrid a Tetuân, pág. 171-72.

Hispania, LVI/, túm. 192 (1996) 93-114 
( «la visión de aquella joven agraciada, limpia y hacendosa, con el sello de la agreste virtud en su porte tranquilo y sereno, me causó profunda simpatía») ${ }^{64}$. En conjunto, los contactos con los marroquíes se reducen a los márgenes de la sociedad (intérpretes, expatriados, renegados, judios y, en otro extremo, altos funcionarios, visires, diplomáticos), y están profundamente afectados por cuestiones de género, etnia y clase social. Esto no impide, por otra parte, que los viajeros crean disponer de un conocimiento suficientemente amplio de la población y que expresen juicios definitorios sobre su carácter, vicios y virtudes.

La apreciación de los habitantes de Marruecos es uno de los aspectos que mejor revelan la retórica de la dominación a que me he referido con anterioridad. La constatación de la decadencia absoluta del país va acompañada de la reducción de los marroquíes a una conducta estereotipada; no hay individualidades, sólo tipos generales. Los ejemplos de este mecanismo reductor son abundantísimos y siempre descalificadores: son astutos, trapaceros, fanáticos... repertorio bien conocido y que a veces admite alguna matización, como la que hace Gatell sobre los habitantes del Sūs ${ }^{65}$. El marroquí no está civilizado, por tanto carece de las "virtudes" que acompañan a ese estado superior de la sociedad. «Los árabes son como niños», dice Mitjana "6, identificando esa situación con la de los pueblos primitivos. Más aún, en algunos casos se llega a despojar a los seres humanos que se contempla no sólo de su individualidad, sino también de su entidad como personas. Villa-Urrutia ve en Marrakech «cadáveres ambulantes, mal cubiertos sus descarnados miembros con los mugrientos jirones de un jaique" ${ }^{67}$. Alarcón, al relatar uno de sus desesperados intentos por trabar conocimiento con las mujeres tetuaníes, cuenta con gracioso estilo cómo atrajo la atención de una joven en una azotea cercana, por el procedimiento de arrojar dulces para que los recogiera: «Siguen gustándole los dulces, y yo sigo echándoselos los días que vengo, como acabo de echárselos hoy. Pero se los arrojo uno a uno, obligándola a hacer antes algunas pantomimas y monerías ... Del propio modo se enseña a una perra de aguas a ponerse en dos pies» ${ }^{68}$. Esta «animalización» de las personas, la negación de su existencia como tales para identificarlas con estadios vitales inhumanos es un recurso común a otros viajeros europeos del mismo periodo, que reafirman de ese modo lo que consideran su superioridad moral ${ }^{69}$.

\footnotetext{
64 Melilla, pág. 40-42 y 108.

6s "No son tan viciosos como los de las provincias septentrionales del imperio: ellos salvo algunas escepciones no fưman, ni toman polvo, ni café, ni té, ni opio, ni juegan, ni beben licores, ni hay alli tantos embaucadores, falsos santos, locos y holgazanes que viven a costas agenas, como sucede en otras partes. En general son devotos, pero creo que tienen formada una idea de su religión más racional que otros musulmanes, o a lo menos no hacen tantas esterioridades ni ostentan tan afectado entusiasmo religioso para que el vulgo los respete y tenga por buenos» (Espedición, pág. 128).

66 En el Magreb-el-aksa, pág. 137.

67 Embajada, pág. 53.

68 Diario, II, pág. 251.

69 Véase GREGORY, D. op. cit., pág. 35, a propósito de Florence Nightingale.
} 
La jerarquía personal así establecida se complementa con otra de carácter cultural, que se manifiesta en la apreciación de los monumentos artísticos y en la calificación del devenir histórico de los árabes en general y de los marroquíes en particular. En los relatos de viaje a países como Egipto, Siria o Palestina, es frecuente observar en los viajeros occidentales una tendencia a la búsqueda del pasado pre-islámico; el caso de Egipto es quizá el más notable y puede ponerse en relación con la reivindicación del pasado romano en Argelia y Túnez por parte de viajeros y estudiosos franceses ${ }^{70}$. Las reminiscencias bíblicas son también abundantes, y algunos de los viajeros españoles a Marruecos rememoran ese contexto en alguna ocasión ${ }^{71}$, pero lo que predomina en todos ellos es la sensación de una vuelta al pasado, de un regreso a la Edad Media.

De ese modo, el viajero atraviesa por un desplazamiento espacial y temporal que funciona en un doble sentido: el del hecho físico del viaje y el de su representación imaginada, que se sitúa en una geografía imaginaria de contornos míticos y de siglos pasados. Con la particularidad de que ese viaje metafórico al medievo está llevando al viajero español a un tiempo histórico que no comparte con otros viajeros occidentales: el mundo de al-Andalus.

No todos los viajeros son conscientes de ese íntimo contacto establecido en tiempos pasados entre las dos orillas del Estrecho, unidas durante siglos por una misma cultura islámica. Uno de los más explícitos a este respecto, Alarcón, considera su primitivo anhelo por conocer Marruecos, natural en quien había pasado su niñez "en las ruinas de alcázares, mezquitas y alcazabas», como una pasión juvenil, sustituida en el momento de su viaje por el convencimiento de la misión civilizadora de España ${ }^{72}$. La construcción del exotismo del pasado, tan llena de reminiscencias literarias, se observa sin embargo nítidamente en su identificación de Tetuán con las ciudades árabes del pasado: "Tetuán... era la Granada del siglo XIV; era Damasco; era Medina; era Ispahan... visitar a Tetuán equivale a ver a Córdoba en el siglo xmr..." ${ }^{73}$. Hay en

70 FRÉMEAUX, J., «Souvenirs de Rome et présence française au Maghreb: essai d'investigation», en Connaissances du Maghreb. Sciences sociales et colonisation (Paris, 1984) págs. 29-46. Del mismo modo, PONS BoIGuEs, en su viaje a Argelia y Túnez antes citado, presta una atención especial a Jas huellas de la civilización romana, que le interesan mucho más que la arquitectura islámica, a pesar de su condición de arabista. La arqueología clásica como tema literario en el $\mathrm{s}$. XIX ha venido siendo objeto de estudio por Ricardo OLMOS en una serie de trabajos que, bajo el título genérico de La arqueologia soñada, ha publicado en Revista de Arqueologia: «La reconstrucción de Pompeya; Bulwer-Lytton y William Gell, recreadores de la luz y la vida» (núm. 142 (1993), 50-57); "Una noche en Pompeya' de José Ramón Mélida» (144 (1993), 52-57); «La 'Isis' de Gerardo de Nerval» (146 (1993), 46-53); «'Spirite' de Théophile Gautien» (154 (1994), 44-55). Del mismo autor, cfr. "Lecturas del arte antiguo en la literatura espaffola del siglo XIX», Actas de las VII Jornadas de Arte: Historiografia del arte español en los siglos XXX y XX (Madrid, 1995), 171-185.

${ }^{71}$ Como Villa-Urrutia (Embajada, pág. 43): «Tiene algo de biblico la presentación de los portadores de la muna que, despues de saludar al Embajador con el acostumbrado marja bebic (bienvenido), depositan en el suelo sus ofrendas"».

72 Diario, I, pág. 8-9.

${ }^{73}$ Ibidem, II, pág. 66, 90 .

Hispania, LVIJ, núm. 192 (1996) 93-114 
éstas y otras apreciaciones semejantes una evidente voluntad de subrayar la muerte de una cultura o, al menos, su estancamiento en un pasado desaparecido. Al-Andalus como referencia se convierte en una forma de negar el presente, que se vincula con la historia de un mundo perdido. En otros momentos, Alarcón se deja vencer por la evidencia: las casas de Tetuán «recuerdan en su mayor parte las de Andalucía ... ¡Pues Tetuán es Granada! La llanura, los términos de su horizonte, su colorido, su aire, su luz, la comarca en conjunto, todo recuerda completamente la vega granadina. El mismo verdor obscuro, igual lujo de frutales, idénticos caseríos en el campo... ¡Ah! La ilusión es completa” ${ }^{74}$. La similitud no va más allá del aspecto físico, y la frase final es reveladora: se trata de una ilusión, de un engaño de los sentidos para quien se deja llevar por la nostalgia de la patria. Parecida es la reacción del embajador Merry y Colom, al escuchar el canto de los miembros de la cabila que guardaba su campamento: «Recuerda aquella música los cantares de Andalucía, y escuchábala la Legación española en aquel desierto con el placer con que en lejanas y extrañas tierras se oye todo cuanto despierta en el ánimo la dulce memoria de la patria y de la familia" ${ }^{75}$.

En otros viajeros, la conciencia de la existencia de al-Andalus se convierte en uno más de los mecanismos utilizados para descalificar la realidad marroquí. Así, los monumentos arquitectónicos no pueden compararse con los que se conservan en Espana, bien por su inferior calidad o por el estado de abandono en que se encuentran: acreo que convenientemente restaurada la puerta principal del santuario de Ben-Almanzor, figuraría dignamente al lado de los más bellos pórticos de la Alhambra o del Generalife", afirma Mitjana en Marrakech, donde califica al palacio en que se aloja la Legación como uuna especie de Alhambra en bruto» ${ }^{76}$. El palacio del sultán en Tánger es, para Boada, un «edificio que recuerda, por su estilo y primorosos techos, algunos monumentos de la dominación árabe en España, aunque no tiene la riqueza y grandiosidad de éstos" ". Lo mejor y más bello que hay en Marruecos es lo que trajeron de la Península los andalusies, «una civilización más adelantada que la de los marroquíes; civilización que se traduce en sus casas y mezquitas, industrias y costumbres" ${ }^{78}$, cuyo recuerdo aún perdura y cuya pérdida «lloran veinte generaciones, cuya impotencia dejo morir la ira guerrera, y guarda en aquellos cantares el dolor que causa el bien perdido para siempres ${ }^{79}$.

La referencia a al-Andalus en estos viajeros es, por tanto, un modo más de acentuar la distancia entre ellos y su objeto de observación. Al traer a la memoria la historia árabe de la Península e identificarla con la actualidad marroquí, se hunde a ésta en un pasado irrecuperable. Al mismo tiempo se

\footnotetext{
74 Ibidem, I, pág. 89 y 240.

75 Relación, pág. 32.

${ }^{76}$ En el Magreb-el-aksa, pág. 75 y 191.

77 Allende el Estrecho, pág. 12.

78 Ibidem, pág. 282.

79 Del Marruecos español, pág. 176.
} 
establece una comparación desfavorable en relación con un tiempo dorado de la cultura árabe, que se ha dejado perder en el curso de una inexorable decadencia. Pero en ningún momento sienten esos viajeros que al-Andalus les pertenece como dominio histórico propio; todo lo más, sugiere una remebranza fugaz, en la visión de un paisaje o en los tonos de una canción. Y esa memoria de conexión se establece sobre todo con la realidad del sur de España, terreno él también de un exotismo propio, no por cercano menos real y susceptible de convertirse en tópico.

Quisiera terminar con algunas consideraciones finales. En primer lugar, debo insistir en el carácter fragmentario de este texto: los viajeros cuyos relatos me han servido de base no son más que una muestra representativa de un conjunto mucho más amplio. Sus textos tampoco han sido explotados de manera exhaustiva. Las limitaciones de espacio de este trabajo me han obligado a seleccionar únicamente algunos de los recursos utilizados en su discurso sobre la sociedad marroquí, en un intento de mostrar cómo se articula un lenguaje de tipo colonial. Este lenguaje se desarrolla en una situación peculiar y distinta de la que se observa en otros países europeos, donde va de la mano con una expansión territorial triunfante en el Norte de África y en el Oriente Medio. Entre la realidad de la limitada acción española en Marruecos y la retórica empleada por los grupos de presión "africanistas» hay una distancia que explica el radicalismo de algunas posiciones o la insistencia con que casi todos estos viajeros propugnan soluciones y arbitrios para mejorar el papel de España en Marruecos. Comparten con otros viajeros occidentales una retórica del imperio producto de su tiempo, pero le añaden un compromiso personal con la acción de su propio país que no siempre se encuentra en aquéllos. De ese modo contribuyen a formar una imagen de Marruecos y de los marroquíes de su época en la que participan otros muchos autores y que conforma la percepción general de una sociedad por otra, perpetuándose mucho más allá del periodo histórico al que pertenecen. No es un ejercicio inútil comparar lo que escriben estos viajeros con mucho de lo que hoy se publica en España sobre las culturas islámicas y comprobar cómo los recursos retóricos del siglo XIX, bajo formas más depuradas, se mantienen con vigor ${ }^{80}$.

80 Mientras redacto estas páginas, leo en un artículo de prensa: «Junto a la amenaza del integrismo religioso-politico, siempre cuestionable, está, pues, el gravísimo riesgo civilizatorio (sic) que supone la aceptación de unas prácticas sociales que es preciso incluir en el ámbito de la barbarie y el atraso histórico» (Gómez MARIN, J. A., «Islamismos», DIARIO 16, 23.8.95). Cfr. una mirada personal y contemporánea de Marruecos en SuBIRós, P., La rosa del desierto, Madrid, 1994, donde el viajero intenta -con resultados variables - despojarse de su inevitable condición de curista para captar la realidad que le rodea.

Hispania, LV/J, núm. 192 (1996) 93-114 